
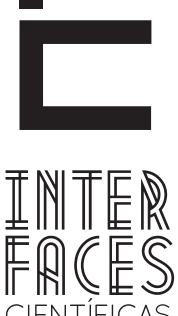

CIENTÍFICAS

HUMANASE SOCIAIS

\title{
ESPECTROS DO PODER: USOS POLLITICOS DAS IMAGENS E DISCURSOS DA IMPRENSA - O JORNAL RIVALE, JUAZEIRO, BAHIA
}

Elson de Assis Rabelo ${ }^{1}$

\section{RESUMO}

Este artigo analisa a produção histórica de sentidos em um grupo de enunciados do jornal Renovação e Integração do Vale, em Juazeiro, Bahia, nos anos 1970. Problematizamos, na relação entre imagens e textos, a veiculação de determinados conceitos e sensibilidades que celebravam os projetos desenvolvimentistas do regime militar para o rio São Francisco. Por meio especialmente da dimensão visual da informação, da política e de práticas como a intervenção nos espaços fluviais, investigamos a singularidade histórica de um momento em que a hegemonia dos governos autoritários nacionais se apoiava em pontos dispersos da sociedade civil, a partir das expectativas pelo progresso.

\section{PALAVRAS-CHAVE}

Imagem de Imprensa. Políticas Desenvolvimentistas. Jornal RIVALE. 


\section{RESÚMEN}

Este artículo analiza la producción histórica de sentidos en un grupo de enunciados del periódico Renovação e Integração do Vale, en la ciudad de Juazeiro, en la provincia de Bahia, en Brasil, en los años de 1970. Problematizamos, en la relación entre imágenes y textos, la vehiculación de determinados conceptos y sensibilidades que celebraban los proyectos desarrollistas del régimen militar para el río São Francisco. A través especialmente de la dimensión visual de la información, de la política y de prácticas como la intervención

\section{ABSTRACT}

This article analyzes the historical production of meanings in a group of enunciates of the newspaper Renovação and Integração do Vale, in Juazeiro, Bahia, in the 1970's. We problematize in the relation of images and texts the transmitting of concepts and sensibilities that celebrated the developmentist projects of military regime to the São Francisco river. Through the visual dimension of the information, politics and practices as intervention in the fluvial spaces, we en los espacios fluviales, investigamos la singularidad histórica de un momento en lo que la hegemonía de los gobiernos autoritarios nacionales se apoyaba en puntos dispersos de la sociedad civil a partir de las expectativas del progreso.

\section{PALABRAS CLAVE}

Imagen de prensa. Políticas de desarrollo. Periódico RIVALE.

search the historical singularity of a moment when the hegemony of the national authoritarian governments was supported by dispersed points of civil society, motived by the expectations of progress.

\section{KEYWORDS}

Image Press. Developmentist Policies. RIVALE Newspaper. 


\section{INTRODUÇ̃̃O}

\author{
Cresce um lamento no seio \\ do povo... cresce um lamento! \\ A ele, junto minha voz \\ sentindo-a, neste momento, \\ acentuada de mágua, \\ funda e remansosa mágoa! \\ Porque aceito o que está feito. \\ Concordo, onimodamente, \\ Com o que me exige o progresso. \\ E glorifico o futuro \\ da região sanfranciscana \\ mesmo com o sacrifício das cidades atingidas \\ pelas águas que serão \\ represadas na terrível... \\ barragem... de Sobradinho... \\ Tenho os olhos no futuro. \\ Vejo as indústrias chegando. \\ Pesados investimentos \\ da grande empresa privada. \\ E mais oportunidades \\ de trabalho a quem precisa. \\ E a terra se povoando \\ se cosmopolitizando, \\ turistas nos procurando \\ o clima se transformando \\ melhorando nossa vida; (BANDEIRA, 1975, p. 5).
}

O poema com que iniciamos este texto é de autoria de um dos jovens intelectuais que se movimentavam na cena artística e política dos anos 1970, em Juazeiro, na Bahia. Joseph Bandeira integra uma geração de filhos das elites locais que, por meio das letras, das artes e da imprensa, se envolveram na reconfiguração dos espaços do Vale do rio São Francisco naquele momento. Seus versos livres, com neologismos como a palavra "mágua", desembocavam como torrentes numa prosa de indignação pessoal e ao mesmo tempo de assentimento político, que demarcavam sua inserção no momento então vivido por aquela sociedade:

Longe do tumulto das sessões plenárias do Congresso, das discussões de gabinete, das aritméticas políticas, das resoluções ministeriais, dos tão divulgados, mas, sempre duvidosos, [...], ouço o clamor das multidões crescendo, vejo o problema sociológico estrugindo, as famílias inquietando-se, as indenizações amesquinhando-se, a harmonia social despedaçando-se, o medo grassando nas almas, a incerteza do futuro compungindo os corações, o desarraigamento violento do apego às tradições do passado, trespassando os peitos que, em horas como estas, nunca se calam... nunca se poderão deixar ficar emudecidos. (BANDEIRA, 1975, p. 5).

A que ele se refere? À construção da Barragem de Sobradinho, iniciada em 1973 e concluída no final de 1977 e início de 1978, que alterou indelevelmente o curso do rio São Francisco, promoveu o deslocamento da população dos municípios baianos de Sento Sé, Pilão Arcado, Casa Nova e Remanso, trouxe a eletrificação e impactou de maneira decisiva os rumos da navegação fluvial. A margem de enunciação de Joseph Bandeira era, portanto, delica$\mathrm{da}$, tendo em vista que, tratando-se de um projeto do regime militar, com uma ampla legitimidade social construída pelos discursos de engenheiros, de políticos e da imprensa, e com pouca possibilidade de crítica, a construção era celebrada junto com seus desdobramentos no sentido do esperado desenvolvimento do Vale, mesmo que o poeta quisesse fazer coro aos lamentos.

0 presente texto se propõe a discutir aspectos dessa margem política de celebração e de produção do consentimento social com as obras chamadas desenvolvimentistas das instituições do Estado para o São Francisco, para seus fluxos e para suas margens, em especial num sub-recorte espacial estratégico assumido pelo jornal juazeirense Renovação e Integração do Vale (RIVALE), num momento específico dos anos 1970, quando se vivia o auge das intervenções do governo autoritário sobre os espaços brasileiros. Tomamos esse jornal como documento, em especial a articulação entre imagens e textos (MENESES, 2003, p. 27; LUCA, 2008; FONTCUBERTA, 2011), para a construção da seguinte problemática histórica: como se dava a ver as práticas e suas imbricações políticas? Como se recorria à dimensão visual para fazer crer, sentir e imaginar que ocorria uma participação na história, pela fabricação de determinada memória do poder? 


\section{A IMPRENSA LOCALE 0 DESENVOLVIMENTISMO}

Em fevereiro de 1972, o presidente Emílio Garrastazu Médici lançou o Projeto para o Vale do São Francisco (Provale), que foi amplamente noticiado pela imprensa, com matéria na revista Realidade, de circulação nacional, e repercussão em periódicos locais. Mas em que consistia o Provale? Nos anos 1940, depois de considerável produção de imagens e discursos por engenheiros e geógrafos e da negociação política vencedora entre deputados, foram criadas duas instituições para o recorte geopolítico que então surgia como objeto de preocupação do Estado nacional: a Comissão do Vale do São Francisco (CVSF), com fundo permanente de $1 \%$ das receitas do país, e a atribuição de atuar em várias áreas, como educação, transportes, agricultura, regularização do rio para a navegação; e a Companhia Hidrelétrica do São Francisco (CHESF), com a tarefa mais limitada de investir na eletrificação. Pioneiras na aplicação do conceito e da prática do planejamento regionalizado, a elas se acrescentou a presença da Superintendência do Desenvolvimento do Nordeste (SUDENE), criada em 1959, para superar o retardamento que se dizia que viviam aqueles espaços (NOVAES, 1989, p. 52).

No final dos anos 1960 , com poucos dos seus objetivos alcançados e acusada de corrupção, a CVSF foi substituída pela Superintendência do Vale do São Francisco (SUVALE), numa reestruturação institucional que se tornou típica dos governos militares, em sua preocupação estratégica com infraestrutura e com a construção do "Brasil grande", tido como "potência mundial". Era também um redirecionamento das práticas de intervenção, que iria focar muito mais em agricultura irrigada, e descurar, por exemplo, da navegação, dada a predominância dos transportes rodoviários no país desde o final dos anos 1950, enquanto a CHESF já tinha iniciado das obras na zona de Paulo Afonso. Como principal programa do começo dos anos 1970, o Provale iria aglutinar e materializar projetos das diferentes instituições com vistas ao desenvolvimento efetivo, que se dizia haver sido abandonado antes do regime militar.
Isso significava também que, no período do chamado milagre econômico brasileiro, e no nível dos espaços considerados atrasados e já estrategicamente recortados e estabelecidos - como o Nordeste, a Amazônia e o Vale do São Francisco -, os governos militares assumiam o desenvolvimentismo com outras práticas e mesmo com outras instituições, com vistas a promover o crescimento econômico e conectar o país com a economia internacional, à custa de empréstimos, mantendo o controle político em negociação com as elites locais e reforçando o discurso nacionalista. Todas essas propostas seriam consolidadas dentro do Plano de Metas e Bases para a Ação do Governo, de 1970, e do I Plano Nacional de Desenvolvimento, de 1971 (EARP; PRADO, 2003, p. 221).

Em março de 1972, na cidade de Juazeiro, na Bahia, um grupo de jovens profissionais liberais, como Flávio Luiz Ribeiro Silva, economista, Paganini Nobre Mota, físico, e Jorge Khouri Hedaye, agrônomo, se reunia para fundar o que seria chamado de "nova etapa da imprensa interiorana", pela criação do jornal "Renovação e Integração do Vale" (RIVALE). Contando ainda com a participação de intelectuais tradicionais, como o ex-barqueiro Ermi Ferrari Magalhães e o comerciante Walter Dourado, que mantiveram colunas frequentes; o periódico surgiu se dizendo atento às questões sociais consideradas mais urgentes naquele momento. Seu título e, eventualmente, suas matérias, assumiam um trabalho estratégico de metonímia discursiva e política sobre o recorte espacial do Vale, a partir de uma área que a Geografia havia chamado de Submédio São Francisco, embora fosse sabido que, a rigor, esse recorte era extensivo a um espaço mais largo dentro do Brasil.

Apesar de o Vale ter sofrido intervenções em outros momentos, o jornal considerava sua fundação um marco temporal, a que a aposição da denominação espacial deveria fazer jus: 
Não poderia haver melhor escolha do que este nome, uma vez que a época se caracterizava pelo início do interesse da União Federal pelos problemas que afligiam as populações ribeirinhas. Juazeiro dava, pois, um passo acertado, convocando os intelectuais citadinos para integrarem a equipe que haveria de fazer o jornal. (DOURADO, 1974, p. 4; CHILCOTE, 2006, p. 252).

RIVALE dará continuidade à tradição periodística local, exemplificada em jornais como 0 Pharol, que circulava na cidade vizinha de Petrolina, em Pernambuco, e o juazeirense Tribuna do Povo, mas já trabalhando com outras possibilidades gráficas de editoração, com a produção de eventuais cadernos especiais, e com maior uso de imagens ilustrativas, como mapas e fotografias, e para estas últimas frequentemente recorria a estúdios fotográficos particulares, como o Foto Tavares e o ArtFoto Paulista, mas raramente se atribuía autoria às imagens. Ainda em termos de recorte espacial, RIVALE se mostrará abrangente, procurando, às vezes, veicular notícias de espaços por onde o jornal também circulava, e que não era limitada a Petrolina e Juazeiro, mas abarcava vários municípios ao redor e que fossem alvo de investimentos públicos ou privados, como Curaçá, Sento Sé, Pilão Arcado, Remanso e Casa Nova, no lado baiano, e Santa Maria da Boa Vista, no lado pernambucano, dentre outras (SANTOS, 2001, p. 5-9).

Tal abrangência era justificada, também, por um discurso de afirmação do cumprimento de certa missão assumida pelo jornal, qual seja de conexão com os processos econômico-sociais que estavam acontecendo e mesmo como vetor dessa transformação, por meio da divulgação de conceitos e práticas:

Sempre voltado para a defesa dos interesses regionais, procurando cada vez mais valorizar o homem sanfranciscano colocando-o sempre no seu lugar de destaque dentro de todo este potencial que hoje começa a se dinamizar.

Procurando cada vez mais promover e proclamar pelos mais distantes rincões da Pátria o vale sanfranciscano, sua história, sua gente, seus costumes e o seu trabalho, o RIVALE sente hoje, ter cumprido a missão a que se propusera desde a sua fundação. É responsável também por esta onda de desenvolvimento e progresso que invade toda esta região. (RIVALE, 1975, p. 1).
Desde os meses iniciais de 1972, RIVALE se relaciona com as questões políticas, como o lançamento do Provale, mas, como é próprio à definição histórica de regras no discurso da imprensa, buscava ajustar sua linguagem, no sentido de procurar demonstrar imparcialidade, não demonstrar filiação partidária, mas sem deixar de demarcar a mudança que se dizia ser perceptível:

\begin{abstract}
A ação do PROVALE, sendo específica agora, com melhor padrão e qualificação de princípios, normas e metas, deve atender ao grito das populações que anseiam pelo aproveitamento maior de nosso rio, com a irrigação das grandes terras, o fortalecimento das cidades na realização de obras básicas como energia, água, saneamento e estradas. (SÁ, 1972, p. 3).
\end{abstract}

Ao vir à luz no mesmo momento do Provale, o jornal surge como acontecimento discursivo, uma intervenção daquele grupo de intelectuais na cena social e na disputa pela reconfiguração dos espaços (FOUCAULT, 1996; MAUAD, 2005). A construção da Barragem de Sobradinho, também conhecida como Projeto Sobradinho, entre 1973 e 1978, no território do município de Juazeiro, acenava como um exemplo de grande porte dessa reconfiguração. Esse empreendimento, bem como a camada discursiva responsável por sua enunciação, de que o melhor exemplo é o jornal RIVALE, tem seu lugar situado em relação à trama política que o envolvia.

A centralidade no campo das práticas foi conferida ao Projeto Sobradinho por ser uma obra de eletrificação, de competência, portanto, de uma instituição com fama de estabilidade como a CHESF, e é daí que se entende porque RIVALE tendia a publicar repetidamente matérias sobre a Barragem, num momento em que, não obstante, várias instituições também atuavam conjuntamente naqueles espaços, como a SUVALE e a SUDENE, e em que as elites locais percebiam as vantagens de apoiar as iniciativas desenvolvimentistas, na medida em que aspectos sociais como a estrutura fundiária não corriam risco: para os projetos de agricultura irrigada, as relações de trabalho e de propriedade seriam mantidas; para as perdas de terras por conta de inundações advindas das barragens, seriam devidamente pagas indenizações (SILVA, 2001, p. 82). 


\section{AS FIGURAS DOS GOVERNANTES E OS ESPAÇOS DO PODER}

Um dos primeiros empenhos do jornal foi o de veicular um grupo de vozes concorrentes sobre o Projeto Sobradinho: dos grupos sociais que defendiam as vantagens da obra, incluindo a regularização da vazão do rio para dotar de força hidráulica suficiente a Usina de Paulo Afonso tornando-a independente da ocorrência de secas que baixavam periodicamente o curso fluvial -, e a agricultura irrigada a partir do lago artificial a ser criado, de acordo com a expectativa por projetos de irrigação; e dos outros grupos preocupados com a manutenção da navegação e a transferência populacional advinda da inundação dos municípios baianos afetados pela Barragem (DOURADO, 1975, p. 4). RIVALE apresenta eventualmente faces distintas do problema, mas se posiciona, de modo geral, em seu conjunto de enunciados, na seleção dos temas e na forma de sua publicação nas colunas e seções de notícias, a favor da obra, o que, obviamente, era uma tônica dominante da imprensa.

A coluna "Sobradinho é notícia", bastante regular e sem atribuição de autoria, havia sido criada para acompanhar e noticiar de forma detida o andamento das obras da Barragem, os capítulos da desocupação das antigas sedes municipais e da edificação das novas, o pagamento de indenizações, as alterações sofridas no Projeto inicial e o cumprimento dos prazos, as visitas periódicas do engenheiro-responsável Eunápio Peltier e de outras autoridades regionais e nacionais preocupadas em equacionar os problemas surgidos com o empreendimento. Em diferentes momentos, mas com ênfase quando da proximidade dos aniversários da obra, a coluna informa, com boa dose de disfarce dos conflitos, a respeito dos "entendimentos amigáveis para desapropriação e relocação de propriedades e benfeitorias" (RIVALE, 1974a, p. 7).

Além de Eunápio Peltier, outras autoridades visitavam as obras da Barragem e o periódico elaborava tais visitas enquanto eventos, com o recurso das imagens fotográficas. Em 1973, antes de assumir a presidência da República, Ernesto Geisel viaja ao Vale e visita o Projeto Bebedouro, de agricultura irrigada, em Petrolina, o Projeto Sobradinho e a Companhia de Navegação do São Francisco, em Juazeiro (RIVALE, 1973b, p. 8). A primeira notícia da visita de Geisel vem na capa da edição do jornal, com um retrato do general à esquerda e, abaixo, uma foto da paisagem fluvial, do lado juazeirense. A segunda foto está ladeada pelos dizeres “O poema é o rio", título de um poema em prosa com tom naturalista, sem autor indicado, que humaniza o "rio vaidoso" e o desloca de seus usos sociais - exatamente o contrário do que Geisel fora buscar em sua visita, que era o "aproveitamento econômico" do rio (Figura 1). Esse tipo de organização das imagens e textos, pela edição, é indicativo da associação, por conotação retórica linear, da figura política de Geisel àqueles espaços, num momento de expectativa pelo que o futuro presidente pudesse fazer pelo Vale (RIVALE, 1973a, p. 1; BARTHES, 1990, p. 19-21; BOLTANSKY, 2003).

Figura 1 - "Geisel no Vale"

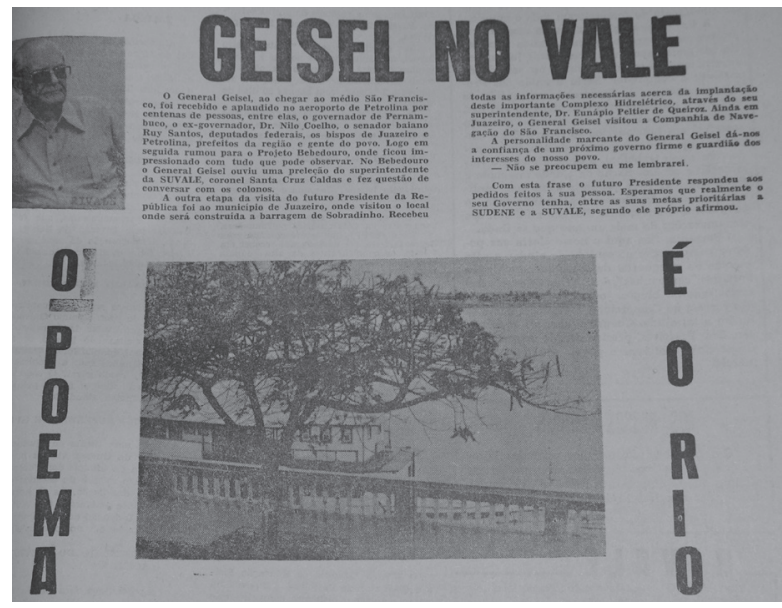

Fonte: RIVALE (1973, p. 1).

Na ocasião da visita do governador baiano Roberto Santos, a imagem utilizada na capa é uma colagem com o mapa da chamada região administrativa de número 5, do território baiano, e o rosto do governador (Figura 2), tendo acima a manchete que dizia "Roberto Santos veio ouvir reinvindicações". 0 trabalho de 
edição remete às vanguardas artísticas da fotomontagem do começo do século XX, mas se presta a um uso político (FREUND, 2011). De modo mais explícito que no exemplo do presidente Geisel, a imagem da face do governador, aqui, é integrada ao mapa, de modo a acentuar o caráter político-administrativo da representação cartográfica (BLACK, 1997), dando a ver não apenas o espaço reduzido ao mapa, mas o nexo de dependência e submissão para com o indivíduo que ocupava o cargo na hierarquia política. Ao mesmo tempo, o editorial de RIVALE elabora um discurso que convoca a participação do governo estadual para lidar com o impactante desdobramento da obra que era a inundação dos municípios:
Falar sobre o inesgotável manancial de problemas que encerra a construção da barragem de Sobradinho parece até desnecessário. Ao lado dos notórios benefícios que a barragem trará, se não houver por parte do Governo Estadual um sólido assessoramento no processo de transferência dos habitantes das cidades inundadas, e na posterior criação de condições de sobrevivência, a atuação do Governo Federal isolada pode não ser eficaz. Remanso, Pilão Arcado, Casa Nova e Sento-Sé, marcadas pelo às vezes trágico destino do progresso, merecem e devem ter todo o apoio do governo da Bahia para que os benefícios sejam reativados, ou manipulados com mais sensatez, não acontecendo o que muito se teme: um êxodo em massa dessas populações, para as maiores cidades da região, ou a decadência prévia das novas cidades. (RIVALE, 1974c, p. 2).

Figura 2 - Colagem do rosto do governador Roberto Santos e do mapa da região administrativa n. ${ }^{\circ} 5$, do território baiano

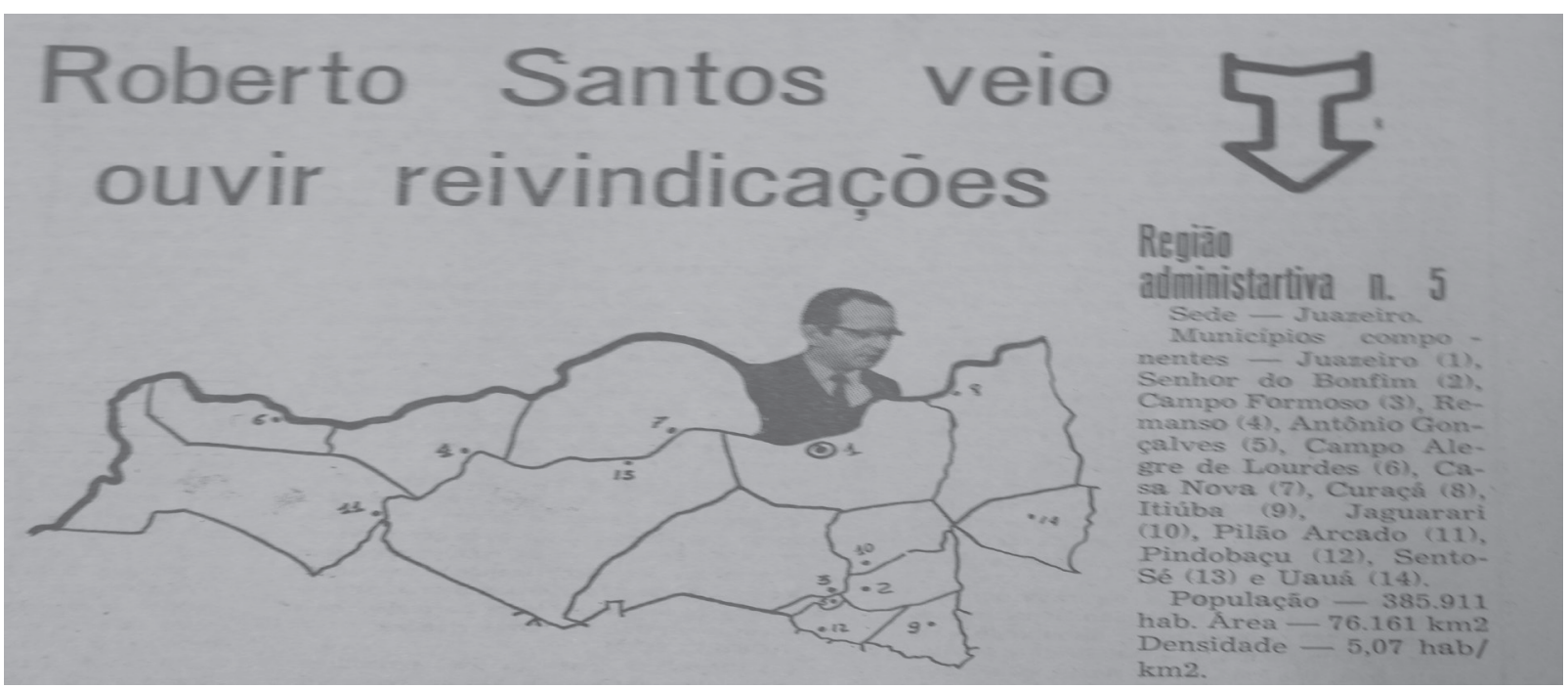

Fonte: RIVALE (1974b, p. 1).

No Caderno Especial Sobradinho Ano 1, os textos são pequenos relatórios das atividades dos governantes locais e expectativas laudatórias sobre o deslocamento, como nos dizeres a seguir: "SENTO-SÉ, uma cidade que muda de local mas continua sempre viva" [maiúsculos no original];
“A nova Pilão Arcado surgirá em breve com novas perspectivas de progressos constantes, uma esperança viva do seu povo". Igualmente, junto a esses textos, aparecem colagens com fotos de pequenos trechos da área urbana dos quatro municípios a serem inundados e retratos em close-up de cada 
prefeito em sua respectiva cidade, relacionando suas imagens aos espaços (Figura 3). Nesse momento em que a experiência urbana peculiar desses espaços marcadamente rurais se desagregava, com os possíveis perigos de reordenamento dos seus laços sociais, de migrações em massa, de perda irrecuperável de atividades econômicas como a pecuária, essa vinculação visual conotada nas colagens pode ser lida como uma herança da tradição política que os observadores do passado chamavam pejorativamente de feudais.

Mas as colagens, também, comportavam outras leituras possíveis. As colagens, ao exibirem recortes das cidades como metonímia de espaços maiores, que incluíam as zonas rurais quase nunca aceitáveis no plano do visível construído por RIVALE, enquanto os rostos dos prefeitos apareciam em fotos justapostas, funcionam, também, como meio de exibição do domínio político que abrangia cada um daqueles territórios apesar das mudanças. Num apelo a formas históricas e visuais inclusive da cultura religiosa daqueles grupos sociais, as fisionomias dos prefeitos flutuando por sobre as cidades remetem a santos ou espectros a velar por elas, reiterando o controle, a vista de cima, que eles teriam sobre as transformações espaciais que estavam ocorrendo (GINZBURG, 2014).

Figura 3 - Colagem com foto da cidade de Casa Nova e retrato do prefeito Clodoaldo da Silva Castro

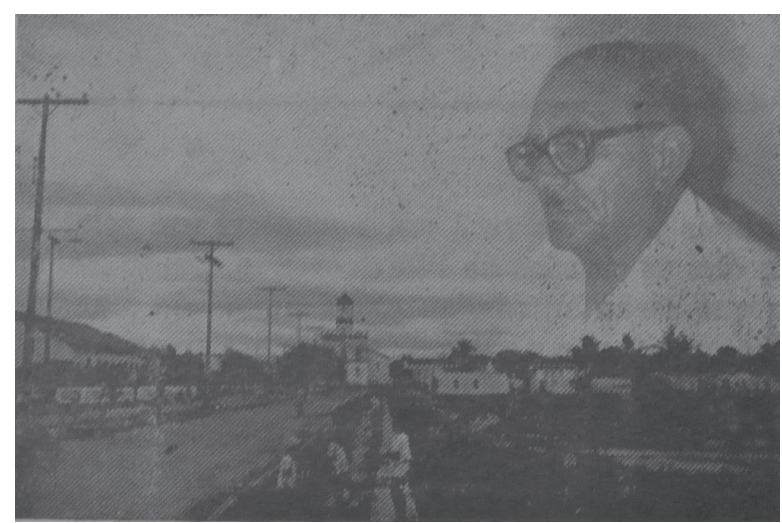

Fonte: RIVALE (1974b, p. 2).

\section{SOBRADINHO: O VISÍVEL E O INVISIIVEL DAS DISCÓRDIAS}

Voltemos ao fluxo de enunciados sobre a Barragem. De 1976 a 1977, avançada a construção, o destino dos municípios e populações estava selado, parte das famílias veio a se instalar nos arredores do lago artificial criado pela inundação, outra parte no Projeto de Colonização da Serra do Ramalho, em área então pertencente ao município baiano de Bom Jesus da Lapa, a centenas de quilômetros dos espaços de origem. RIVALE aumentava a expectativa pela conclusão da obra, com o recurso a matérias de primeira página, a manchetes em grande tamanho e ao uso de imagens. Exemplo disso é a frequente colocação na instância enunciativa de eventos como a transferência das populações e o comparecimento de figuras importantes da política nacional na inauguração das obras, em momentos-chave do desvio do rio, de seu represamento parcial e total, considerados, a partir de uma referência visual, não apenas acontecimentos dignos de ser noticiados, mas "como espetáculo histórico para o povo sanfranciscano, que verá ser mudado o curso normal do lendário e secular Rio da Integração Nacional” (RIVALE, 1976c, p. 1; FONTCUBERTA, 2011, p. 42).

Vamos nos deter no relato desses instantes específicos nos quais a narrativa do periódico toma a forma de uma epopeia que abusava dos lugares comuns sobre o São Francisco, como no epíteto citado acima, remetia aos escritores do passado e estendia o conceito de desenvolvimento sinalizado naquela transformação dos espaços. De acordo com uma tônica recorrente na propaganda da época, os heróis da narrativa eram: as instituições, os engenheiros, os governantes e, em menor medida, as populações por seu sacrifício involuntário em favor do progresso (FICO, 1997).

Em abril de 1976, RIVALE anunciava a transferência de 30 famílias, e para isso lançava mão de um enunciado cuja diagramação colocava duas fotografias ao lado 
do texto escrito. A sintaxe linear proposta implicava na articulação entre as duas imagens, postas uma embaixo da outra, e entre texto, legendas e imagens, de modo a conotar o trabalho de deslocamento fluvial do grupo de pessoas (Figura 4) através do barco a vapor, numa época de tentativa revalorização da navegação e da sua utilidade. 0 texto, por sua vez, dizia:

\begin{abstract}
O primeiro grupo de famílias será transferido, sem ônus para a população, via fluvial, no dia 28 de abril, para as primeiras 30 casas construídas na Agrovila número 5, em Bom Jesus da Lapa.

Essas famílias são oriundas do distrito de Santana do Sobrado e do distrito de Intãs, ambos pertencentes ao município de Casa Nova. Formam um grupo de 160 pessoas, crianças e adultos, e seguiram para o Projeto no Vapor São Salvador, fretado da C. N. S. F. Esse vapor rebocava uma balsa onde foram transportados todos os pertences das famílias; os animais pertencentes às famílias transferidas foram transportados em balsas adaptadas a este tipo de carga. (RIVALE, 1976a, p. 7). [grifo nosso]
\end{abstract}

Ora, em que pese a indecisão do texto entre os tempos verbais conjugados (pretérito, presente, futuro, no mesmo pequeno trecho), e a dificultosa análise que isso acarreta, a Figura 4 mostra a significativa posição de braços cruzados das pessoas que aparecem aglomeradas na margem do rio. Essa posição talvez se referisse, efetivamente, a sua incômoda situação de espera pela viagem, deles próprios e de seus bens. A legenda diz tratar-se do "primeiro grupo" e acaba servindo ao uso de RIVALE para a conotação editorial da notícia do evento - estaria ele ainda por acontecer, se atentarmos para o uso do futuro no início do texto? Assim sendo, teria sido a foto aproveitada de outra ocasião e aí utilizada com outro sentido? De todo modo, o enunciado terminou por dar a ver, sem ter tido necessariamente a pretensão, o tempo da espera daquelas populações, que se encontravam na encruzilhada dos debates institucionais sobre seus destinos, sobre a recomposição de sua vida social e a reelaboração das memórias sobre seus lugares de origem. E apesar disso, essa espera parecia buliçosa, como se via na tentativa da CHESF de lidar com as recusas das famílias para irem para a distante Serra do
Ramalho, não obstante as vantagens propaladas (VIDAL, 2008, p. 10-11; 78-79; 84).

Figura 4 - "O primeiro grupo" de famílias deslocadas

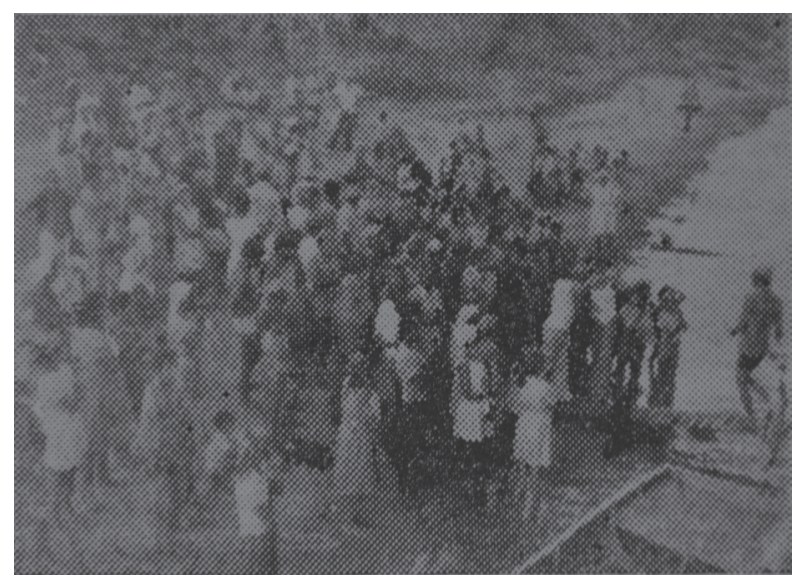

Fonte: RIVALE (10 de abr. 1976a).

Em um sentido mais abrangente, caberia investigar mais a fundo os mecanismos de inserção, de apropriação e de uso, por parte das populações locais, dessas práticas desenvolvimentistas. Certamente, que seu lugar aí não é apenas o de meras vítimas de um processo avassalador, na medida em que táticas como a recusa, ainda que veiculadas de maneira indireta em discursos dominantes como o do jornal, indicam que a hegemonia na produção dos espaços era, se não contestada, pelo menos desviada em relação aos projetos iniciais. Em torno ainda dos discursos, mas também das imagens, e da problematização sobre suas possibilidades obtusas de testemunho sobre as práticas, quando nem sempre é conveniente ou permitido dar a ver determinadas variáveis sociais excluídas do visível, percebemos que a reconfiguração espacial punha em jogo um campo de disputas não-pensado nem mesmo pelo Estado (DIDI-HUBERMAN, 2012, p. 56. 58.133).

No outro polo, o da propaganda afirmativa sobre a Barragem, a articulação entre elementos visuais e escritos era indispensável para a produção de sentidos, nesse momento particular da ditadura, em que não apenas 
existia a censura para coibir os artefatos (KOSSOY, 2007), mas havia, também, grande veiculação de enunciados sobre as obras em andamento por todo o país. Solar, visível, posicionado acima da natureza e da sociedade, das paisagens e das populações, o poder se impunha não apenas por práticas e discursos, mas por sua exibição, como se vê em julho de 1976 (Figura 5).

Figura 5 - "Momento histórico em que o General Adalberto Pereira dos Santos, vice-presidente da República, presença dos governadores da Bahia, Sergipe e Pernambuco, ministro das Minas e Energia, presidente da Eletrobrás e outras autoridades civis e militares, acionava o botão abrindo automaticamente as comportas, desviando o curso do famoso rio São Francisco"

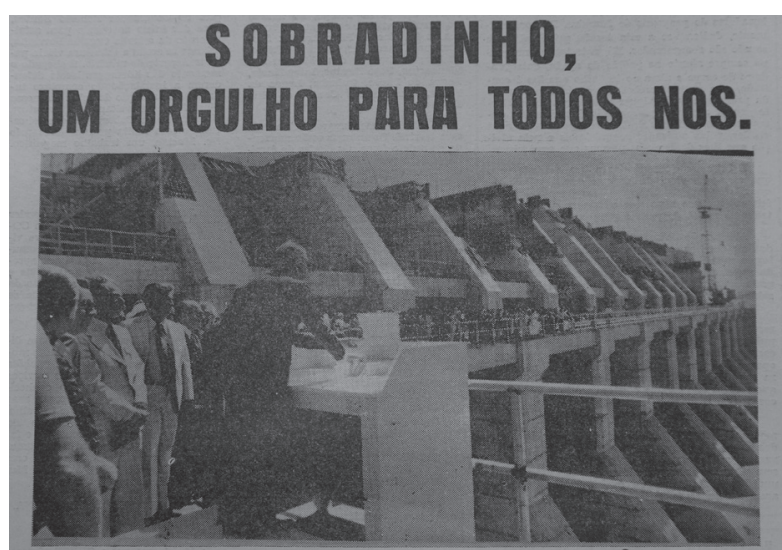

Fonte: RIVALE (1976c, p. 1).

A matéria de primeira página recorre ao sujeito coletivo no título e conclama o leitor a se incluir nele. A foto não tem autoria atribuída e a legenda diz: "Momento histórico em que o General Adalberto Pereira dos Santos, vice-presidente da República, presença dos governadores da Bahia, Sergipe e Pernambuco, ministro das Minas e Energia, presidente da Eletrobrás e outras autoridades civis e militares, acionava o botão, abrindo automaticamente as comportas, desviando o curso do famoso rio São Francisco”. Enquanto a composição da foto estimula o sentimento de reverência política e atualiza o mito moderno do concreto, em suas linhas que ocupam o espaço enqua- drado mais que os indivíduos, a legenda ignora os demais circunstantes, vistos em tamanho minúsculo, e confere o protagonismo às autoridades, que assim se inseriam naquilo que se entendia por "história”, tida não mais exata ou somente como passado, mas como uma temporalidade historicista que se fazia no presente: "o lendário e romântico Rio São Francisco passa a fluir por dentro de monumentais comportas, fato histórico registrado no último dia 12" (BENJAMIN, 1994, p. 222-234; KOSELLECK, 2006, p. 21-40).

O texto cumpria seu papel de retomar as etapas da obra, fazer um balanço do capital investido, justificar as alterações no projeto inicial e celebrar suas vantagens, independente dos impactos sociais e ambientais, para os quais se demonstrava todo o controle, em seus minuciosos aspectos:

\begin{abstract}
Com as obras já em execução desde junho de 1973, a CHESF resolveu, em maio de 1974, incluir no projeto uma Casa de Força, pois o volume de água e desnível causados pela barragem permitiam seu aproveitamento na geração de energia elétrica.

[...].

Para apoiar estas obras gigantescas, a Servix deslocou para o agreste sertão um imenso contingente de homens e máquinas, montando até mesmo uma usina de concreto que é das maiores do Brasil.
\end{abstract}

\section{O LAGO}

[...]. Com o fechamento das comportas, em fins de 1979, um imenso lago cobrirá a região que hoje é composta de caatingas. [...], o lago em muito beneficiará a agricultura da área, castigada por secas constantes; permitirá a navegabilidade do Rio São Francisco em sua quase totalidade e alterará o clima seco da região transformando o árido vale do São Francisco em região de grandes possibilidades econômicas.

Dentro da região do futuro lago, todos os municípios e vilas terão seus moradores, em número de aproximadamente 70 mil, transferidos para novas e modernas comunidades que já estão sendo construídas pela CHESF. [...] [negritos no original]. (RIVALE, 1976c, p. 1).

Um complexo de natureza e cultura, produto da vazão fluvial instável - posto que suscetível a estiagens e chuvas - e do engenho humano que se propunha a vencê-las, a Barragem de Sobradinho aparece no enunciado 
como evento pretensioso e condensador da história dos espaços do São Francisco, que transformaria várias práticas sociais (eletrificação, deslocamento populacional, agricultura irrigada, navegação, combate às secas). Uma história pensada como cumulativa seria assim coroada após uma trajetória que vinha dos estudos do século XIX que buscavam no rio o fundamento da unidade da Nação, passava pelos discursos sobre a integração nacional no século XX e pelos projetos de idealizadores tão distintos como o industrial Delmiro Gouveia, e os engenheiros Geraldo Rocha e Apolônio Sales.

Em dezembro de 1977, na costumeira ritualização do tempo que RIVALE realizava em suas edições de fim de ano, nas quais várias instituições, empresas e autoridades políticas enviavam mensagens aos leitores, a CHESF repetirá a fotografia de julho de 1976, com a legenda informativa de que se tratava de um "flagrante" do desvio do rio, o que parecia pouco provável, se lembrarmos de que sua feitura atentava para a composição do cenário da Barragem como palco da política, ou o tal flagrante simplesmente não é mencionado na primeira edição, que celebra a presença de políticos importantes no represamento parcial do rio. Mas, mesmo repetida, reinserida no circuito da imprensa e usada para promover a memória oficial daquela inauguração, a sobrevida dessa imagem dava mostras de sua força persuasiva, a mercê da retórica da instituição desenvolvimentista que afirmava a conclusão de um processo histórico.

Conectados, portanto, às transformações espaciais no Vale do São Francisco, e veiculando enunciados que celebravam o feito dos indivíduos, grupos sociais e instituições, considerados protagonistas nessas práticas, o periódico se inseria nesse tecido político complexo, a respeito do qual se compreende que o regime autoritário não pôde se impor nem durar sem a própria elaboração de um imaginário social complexo, e por vezes contraditório, do progresso.

Além disso, a problematização dos enunciados, da produção das imagens e dos seus usos políticos, permite tomá-los como vestígio de que vários outros grupos da sociedade civil também participaram dessa hegemonia, por apostarem que espaços frequentemente entendidos como isolados e atrasados seriam, finalmente, alçados à condição de desenvolvidos. Enquanto a historiografia repensa os silêncios acerca dos apoios explícitos ao regime, outras formas, rarefeitas, dispersas, porém efetivas, de consentimento e de depósitos das expectativas nas práticas promovidas naquele momento, em espaços diversos do Brasil, merecem nossa investigação (REIS FILHO, 2010; FOUCAULT, 2003, p. 241-250).

\section{REFERÊNCIAS}

1972-1975 - 3 anos promovendo o Vale. RIVALE, Juazeiro, ano IV, n.132, 15/16 de mar. 1975, p.1.

30 FAMÍLIAS transferidas. RIVALE, Juazeiro, ano V, n.182, 10 de abr. 1976 [1976a], p.7.

A SOLUÇÃO definitiva... RIVALE, Juazeiro, ano VI, n.235, 5 de jun. 1977, p.4 (Coluna Sobradinho é notícia).

A VISITA de Roberto Santos é sinônimo de esperança. Juazeiro, ano III, n.110, 26/27 de out. 1974 [1974c], p.2.

ÁGUAS do São Francisco serão desviadas. RIVALE, Juazeiro, ano V, n.190, 27 de jun. 1976 [1976b], p.1.

BANDEIRA, Joseph W. Adeus, Remanso. RIVALE. Juazeiro, MAPROL, ano IV, n.167, 15/16 de nov. 1975, p.5.

BARTHES, Roland. A mensagem fotográfica. In: BARTHES, Roland. 0 óbvio e o obtuso. Rio de Janeiro: Nova Fronteira, 1990.

BENJAMIN, Walter. Sobre o conceito de história. In: BENJAMIN, Walter. Magia e técnica, arte e política. São Paulo: Brasiliense, 1994 (Obras Escolhidas, v.1).

BLACK, Jeremy. Maps and politics. Chicago: The University of Chicago Press, 1997. 
BOLTANSKY, Luc. La retórica de la figura. In: BOLTANSKY, LUc; BOURDIEU, Pierre. Un arte medio. Ensayo sobre los usos sociales de la fotografía. Barcelona: Gustavo Gilli, 2003.

Caderno Especial Sobradinho Ano 1. RIVALE, ano III, n.92, , 22/23 de jun. 1974 [1974b], p.2.

CHILCOTE, Ronald $\mathrm{H}$. Power and ruling classes in northeast Brazil: Juazeiro and Petrolina in transition. New York: Cambridge University Press, 2006.

DIDI-HUBERMAN, Georges. Imagens apesar de tudo. Lisboa: KKYM, 2012 (Coleção Imago).

DOURADO, Walter. A energia de Paulo Afonso, os planos de Eletrificação e a Economia do Vale. RIVALE, Juazeiro, ano IV, n.163, 18/19 de out. 1975, p.4 (Coluna História, Tradições, Comentários e Sugestões).

DOURADO, Walter. A nova etapa da Imprensa Interiorana. RIVALE, ano III, n.79, 23/24 de mar. 1974 (Coluna História, Tradições, Comentários, Sugestões).

EARP, Fábio Sá; PRADO, Luiz Carlos. 0 milagre” brasileiro: crescimento acelerado, integração internacional e distribuição de renda (1967-1973). In: FERREIRA, Jorge;

DELGADO, Lucília. 0 tempo da Ditadura: regime militar e movimentos sociais em fins do século XX. Rio de Janeiro: Civilização Brasileira, 2003 (Col. O Brasil Republicano, v.4).

FICO, Carlos. Reinventando o otimismo: ditadura, propaganda e imaginário social no Brasil. Rio de Janeiro: Fundação Getúlio Vargas, 1997.

FONTCUBERTA, Joan. Indiferencias fotográficas y ética de la imagen fotoperiodística. Barcelona: Gustavo Gilli, 2011.
FOUCAULT, Michel. Ditos e escritos: estratégia, poder-saber, v.IV. Rio de Janeiro: Forense-Universitária, 2003. FOUCAULT, Michel. A ordem do discurso. São Paulo: Loyola, 1996.

FREUND, Gisele. La fotografía, expresión artística. In: FREUND, Gisele. La fotografia como documento social. Barcelona: Gustavo Gili, 2011.

GEISEL no Vale. RIVALE. Juazeiro, ano II, n.65, 20 de dez. 1973 [1973a], p.1.

GINZBURG, Carlo. Medo, reverência, terror. Quatros ensaios de iconografia política. São Paulo: Companhia das Letras, 2014.

KOSELLECK, Reinhart. Futuro passado: contribuição à semântica dos tempos históricos. Rio de Janeiro: Contraponto; PUC-Rio, 2006, p.21-40.

KOSSOY, Boris. Mídia: imagens, ideologia, memória. In: KOSSOY, Boris. Os tempos da fotografia. 0 efêmero e o perpétuo. Cotia: Ateliê Editorial, 2007.

LUCA, Tania Regina de. História dos, nos e por meio dos impressos. In: PINSKY, Carla Bassanezi. Fontes históricas. São Paulo: Contexto, 2008.

MAUAD, Ana Maria. Na mira do olhar: um exercício de análise da fotografia nas revistas ilustradas cariocas, na primeira metade do século XX. Anais do Museu Paulista. São Paulo, nova série, v.13, n.1, jan.-jun. 2005, p.133-174.

MENESES, Ulpiano T. Bezerra de. Fontes visuais, cultura visual, história visual. Balanço provisório, propostas cautelares. Revista Brasileira de História, v.23, n.45, São Paulo: ANPUH/HUMANITAS, jul. 2003.

NOVAES, Manoel. Memórias do São Francisco. Brasília: CODEVASF, 1989, p.52. 
NOVAS cidades. RIVALE, Juazeiro, ano III, n.91, 15/16 de jun. de 1974 [1974a], p.7 (Coluna Sobradinho é notícia). O TÉRMINO do ano... RIVALE, Juazeiro, ano VI, n.215, 9 de jan. 1977, p.3 (Coluna Sobradinho é notícia).

REIS FILHO, Daniel Aarão. Ditadura, anistia e reconciliação. Estudos Históricos. Rio de Janeiro: CPDOC, v.23, n.45, jan-jun. 2010, p.171-186.

SÁ, Ary. PROVALE e o Polo Juazeiro. RIVALE. Juazeiro, ano I, n.6. 28 de mai. 1972, p.3 (Coluna Gente e Política).

SANTOS, Andréa Cristina. Mapeamento dos periódicos de Juazeiro-BA e Petrolina-PE (1901-1999). Anais do XXXIV Congresso Brasileiro de Ciências da Comunicação (INTERCOM). Recife: Universidade Católica de Pernambuco, 2011. Disponível em: <http://www.
intercom.org.br/papers/nacionais/2011/resumos/R62924-1.pdf> Acesso em: 13 ago. 2013.

SILVA, Pedro Carlos Gama da. Articulação dos interesses públicos e privados no pólo Petrolina-PE/Juazeiro-BA. 2002. Tese (Doutorado em Economia Aplicada). Instituto de Economia, UNICAMP. Campinas, 2001.

SOBRADINHO, um orgulho para todos nós. RIVALE, Juazeiro, ano V, n.194, 25 de jul. 1976 [1976c], p.1.

VIDAL, Laurent. Mazagão, a cidade que atravessou o Atlântico: do Marrocos à Amazônia. São Paulo: Martins Fontes, 2008.

VISITA do General Geisel. RIVALE. Juazeiro, ano II, n.66, 24/25 de dez. 1973 [1973b], p.8. 